\title{
Development of Diaper using Regenerated Carboxylated Cotton Fiber
}

\author{
Shabrin Farhana.G, N.K.Palaniswamy
}

\begin{abstract}
The article learn and taking place the improvement and portrayal of infant diaper prepared while regenerated cotton fiber of carboxylated. Regenerated carboxylated cotton fiber has been consolidated into the diaper to improve their ingestion limit, liquid strike, centrifuge retention capacity, $\mathrm{PH}$. It is found that the diaper made up of regenerated fiber shows good absorbency when compared to cotton fiber.
\end{abstract}

Keywords:Absorption capacity, acquisition time, liquid strike, centrifuge retention capacity, $\mathrm{PH}$.

\section{INTRODUCTION}

The term medical textiles defines textiles plays major role in medical purposes. Textile materials have both physical and chemical properties and the wide scope of properties, for example, sponginess, adaptability, quality and breathability. The growing part of medical textile is related to social insurance and cleanliness division. Medicinal material utilized purposes ought to be non-unfavorably susceptible, non-cancer-causing, non-harmful.(B.Gupta, R.jain, N.Anjum and H.Singh).The required properties of therapeutic materials are Non-poisonous, Non-hypersensitive, Non-cancer-causing, Antistatic in nature, Optimum weariness continuance, Biocompatibility, fire verification.(GopalakrishnanDuraismay).

In medical textiles major fibers are Natural fibre - Cotton, silk, regenerated cellulose, synthetic fibre- polyester, viscose, lyocell, polyamide, polyvinyalcohol, polyurethane urea, polypropiolactone, polycaprolactone.(Gopalakrishnan D, S Yamunandevi, S Grace Annapoorani)

Diapers are in stable connect with both skin and bodily fluid layers and the person in question wears expendable child diapers amidst synthetic caused diaper it to can be end up in your infant's framework. By utilizing chlorine dioxins are faded, bringing about suffering hints of dioxins. Dioxins are resolved condition poisons that can source a gathering of medical issues including improvement delays, harmed resistance, hormone block certain diseases. Numerous expendable diapers release unstable natural mixes, for example, ethyl benzene, toluene and xylene. As indicated by the EPA, some VOC'are cancer-causing agents. Others can inception neurological issues, eye bothering and decline insusceptibility.(http://www.emedicine.com/emerg/topic374 .htm)

A dispensable infant diapers is made by sandwiching a thinly laid piece of cotton lap with or without absorbent

Revised Version Manuscript Received on 10, September 2019.

ShabrinFarhana.G, Research scholar, Research and Development center, Bharathiar University, Coimbatore, Tamilnadu, India.

N.K.Palaniswamy, Associate professor, Dr.Ambedkar National Institute of Technology, Jalandar, Punjab, India. polymer and super absorbent polymer. In between a lint tissue paper or non woven spun laid material as cover stock or top sheet and a fine significance polystyrene/ polyethylene or spun bond non-woven fabric sheet as back sheet. The streak tissue paper or non woven spun bond fabric portion touches the skin of the child and the liquids are riveted by cellulose fluffy pulp or cotton through the line tissue paper. The size of diaper is length 10.5 ", width 3.25 ", thickness $3 / 8$ " weight $13.5 \mathrm{gm}$ of available product.

Due to dispensable infant diapers it should not be any annoyance of the child's skin and not to be any infectivity of the infant's attire and environment (G Sasikumar, M senthil, $\mathrm{K}$ Visagavel, $\mathrm{H}$ abdulZubar, $\mathrm{T}$ Dheenathayalan).

\section{REVIEW OF LITERATURE}

Characteristic filaments are made by micro fibrils out of fiber in a network of hemicelluloses and lignin. This sort of formation and the compound blend of them is in charge of the usual property to can be watched. Since the characteristic filaments create hydrogen bonds among the long chains, they have the essential firmness and quality. Characteristic filaments are made by microfibrils out of cellulose in a lattice of hemicellulose and lignin. This kind of structure and the concoction creation of them is in charge of the mechanical properties that can be watched. Since the common strands make hydrogen bonds between the long chains, they comprise the fundamental solidness as well as quality.(Brown, R.Malcom, Saxena and I.M.Dordrecht).

Diapers are prepared of material or manufactured unnecessary materials. Material diapers are made out of layers of surface, for instance, cotton, hemp, bamboo, microfiber, or even plastic fibers, or instance, PLA or PU, and can be washed and reused on different events. Superfluous diapers contain porous manufactured mixes and are disposed of after use.

Diapers are essentially worn by infants, little kids who are not yet potty arranged, and by youths who experience bedwetting. They are in like manner used by adults with incontinence, in explicit conditions where access to a toilet is blocked off or for mental reasons. These can consolidate those of forefront age, patients bed-bound in a center, individuals with specific sorts of physical or mental impairment, diaper fetishists, and people working in remarkable conditions, for instance, space voyagers. It isn't exceptional for people to wear diapers under dry suits.(kids health.org)

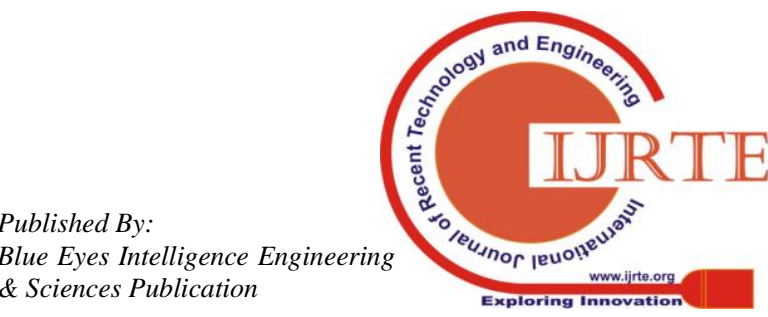


The worldwide infant disposable baby diaper market was esteemed at $\$ 48,121.00$ million out of 2017 , and is anticipated to reach $\$ 78,420.00$ million by 2025 , enrolling a CAGR of $6.3 \%$ from 2018 to 2025. In 2017, the U.S. created the most astounding income, representing extra than one-fifth offer in the worldwide bazaar. Various kinds of diapers produced far and wide incorporate fabric diapers, dispensable diapers, preparing swim pants, nappy, and biodegradable diapers. Fabric diapers are additionally divided into level material diapers, fitted material diapers, pre-overlay fabric diapers, across the board fabric diapers, and others. Consistent ascent in extra cash and different activities taken by the makers to build mindfulness among guardians for child cleanliness in the rising economy has energized the development of the worldwide infant diapers Industry. In addition, diaper bank contain a huge impact in making wellbeing mindfulness among the shoppers.

Slash Powder (SAP) can assimilate and hold very a set of a liquid with deference to its very own collection.

Water-retaining polymers, which are delegate hydrogels while blended, assimilate solution provision through hydrogen holding with water atoms. A SAP's capacity to retain wet relies upon the ionic grouping of the watery arrangement. In deionizer and refined water, a SAP may assimilate multiple era its mass (from 30 to multiple period its very hold capacity) and be able to wind up and about to 99.9\% fluid, however while placed into a $0.9 \%$ salt arrangement, the permeableness drop to roughly multiple period its load.The nearness of valence cations in the course of action obstructs the polymer's capacity to union among the stream atom. (Kabiri, K. (2003).)

\section{III.METHODS AND PROCEDURE}

A. Free swell saline absorptive capacity (iso 17190-7/wsp 240.3) 1

Free swell saline absorptive limit with regards to the Diaper test swatches was resolved utilizing a standard technique (Technical Brochure of Superabsorbent Polymer Research Lab., 2005).

A finely made gadget including a large scale permeable sintered glass channel plate set in a Petri plate $(\mathrm{d}=118 \mathrm{~mm}$, $\mathrm{h}=12 \mathrm{~mm}$ ) was designed. The weigh Diaper test swatch $(0.9 \mathrm{~g})$ was consistently set on top of the outside of polyester cloth situated on the sintered glass. A barrel shaped strong burden (glass beaker with required weight) was put on the dry test swatch. The required weight [applied pressure 0.6(42g] was set on the example (Fig.1). Artificial urine solution $(0.8 \%$ Sodium chloride explanation was extra into refined water and incubated at scope high temperature to dissolve completely to form a colorless solution) was then added equal to the stature of the sintered glass channel and the complete setup was left undisturbed for $60 \mathrm{~min}$. After $60 \mathrm{~min}$, the engorged particle are gauged, and saline absorptive limit was determined utilizing the accompanying condition.

$\operatorname{AUP}(\mathrm{g} / \mathrm{g})=\left(\mathrm{W}_{2}-\mathrm{W}_{1}\right) / \mathrm{W}_{1}$

Somewhere, W1 and $\mathrm{W} 2$ indicate the heaviness of waterless and distended test swatches, correspondingly. The AUP was in use as a calculate of the distended clot might of Diaper materials.

The results are tabulated in Table.1.

\section{B. Centrifuge retention capacity2}

Water or Fluid retention capacity of the materials (fibre, woven, non-woven etc) was evaluated using a standard Centrifuge method.

The radiating information are extra exact than the other assessment techniques (teabag method). About $0.2 \mathrm{~g}$ (W1) of the selected material was located hooked on a bag $(60 \times 60$ $\mathrm{mm}$ ) prepared of nonwoven material. The carrier was dished in $100 \mathrm{ml}$ of synthetic urine result for partially an hour at room heat. It was in use out, and then overload way out was indifferent with a centrifugal barrier ( $3 \mathrm{~min}$ at $250 \mathrm{Xg}$ ). Then, mass of bag (W2) was considered in a digital weighing balance. Similar work was passed out with an empty non-woven bag (without test material). Then the weight of bag (W0) was measured (Fig.2). The inter-particle fluid was clearly detached by this method. The calculated standards were further exact than the teabag method.

The swelling aptitude was calculated by the following equation.

$\mathrm{Se}=\left(\mathrm{W}_{2}-\mathrm{W}_{0}-\mathrm{W}_{1}\right) / \mathrm{W}_{1}$

The results are tabulated in Table.2.

C. Liquid strike through time \& Wetback (ISO 9073-8 \& ISO 9073-14) and Repeated liquid strike through time \& wetback (ISO 9073-13 \& ISO 9073-14) 3,4.

The test carried out using a modified method of EDANA 150.5-02 standard method (Shanmugasundram 2010). A fall of artificial urine resolution was allowed to go down on the Diaper test swatch what's more, the time taken for the answer for vehicle from the upper layer to the inner layer of the Diaper model was calculated. This was estimated by watching the drop firmly with the end goal that dull wet spot was seen on the wet territory of the example. Every one of the examples were adapted for 24 hours before the tests (Fig.3). The results are tabulated in Table.3. Repeated liquid strike through time is the time taken for the transport of liquid after repeated flow. Artificial urine was allowed to fall prior to this method. At that point a drop was permitted to fall on the test swatch and the time taken for the fluid to move is measured and tabulated (Table.4).

Wetback determines the rewet less than load. The heap is connected to invigorate the child weight 4 . It demonstrates the capacity of the diaper test swatch to transport the fluid on to the outside of diaper under burden. This strategy includes running $25 \mathrm{ml}$ of $1 \% \mathrm{NaCl}$ arrangement into test swatch and when the liquid has been assimilated, applying a plate of channel paper (110 $\mathrm{mm}$ distance across) with a mass on top for one minute. The weight is rectangular $(115 \mathrm{~mm} \times 60 \mathrm{~mm})$ with a mass of $1.05 \mathrm{~kg}$ (weight $=1.49 \mathrm{kPa}$ ). The heaviness of liquid consumed by the channel piece was record as the wetback load. A drop of malachite green dye is added to view the absorption pattern on filter paper. Wetback after repeated liquid strike through time is the absorption of liquid after the repeated flow on the test swatch. About $50 \mathrm{ml}$ of $1 \% \mathrm{NaCl}$ solution was permissible to drop on again on the test swatch and the weight is applied. The weight of the fluid absorbed is

Published By:

Blue Eyes Intelligence Engineering

\& Sciences Publication 
recorded as wetback after repeated strike through time. The results are tabulated in Table.5 and Table.6.

D. $\mathrm{pH} 5$

The Diaper will be free from acidic and soluble base material and the $\mathrm{pH}$ of the permeable material will be 6 to 8.5 when tried by the technique given in IS (IS 5405 (1980): Diapers [MHD 14: Hospital Planning]. The hydroxyl ion concentration of the test materials was evaluated using a $\mathrm{pH}$ meter. About $0.2 \mathrm{~g}$ of the test material (Diaper swatches) was cut and dipped onto the distilled water. The tube was kept in a shaker for 20min at $150 \mathrm{rpm}$. The shaker was stopped and the solution containing the test Diaper swatches was exposed under the $\mathrm{pH}$ probe. The probe was well calibrated prior to this analysis using standard buffer solutions. The $\mathrm{pH}$ for the test solution containing the Diaper swatches was recorded and tabulated (Table.7). The $\mathrm{pH}$ was also confirmed using $\mathrm{pH}$ paper (Fig.4)

\section{E. Overall liquid transport characteristics (AATCC 195)}

Overall liquid transport characteristics are the regular speed of fluid wetness absorption from the top and underneath surfaces of the diaper test swatch. The test carried out using a modified method of Masoodi6 et al, 2010. The time taken for the transport of fluid from top and base layer were measured and tabulated.

\section{RESULTS AND DISCUSSION}

Fig 1: Free swell saline absorptive capacity

\begin{tabular}{|c|c|c|c|}
\hline S. No. & $\begin{array}{c}\text { Diaper } \\
\text { test } \\
\text { swatch at } \\
\text { different } \\
\text { psi (0.6 } \\
\text { psi) }\end{array}$ & $\begin{array}{c}\text { Plain } \\
\text { cotton } \\
\mathbf{( g / g )}\end{array}$ & $\begin{array}{c}\text { Carboxymethylated } \\
\text { Cotton(g/g) }\end{array}$ \\
\hline $\mathbf{l}$ & $\mathbf{N}_{\mathbf{1}}$ & 11.5 & 16.7 \\
\hline $\mathbf{2}$ & $\mathbf{N}_{\mathbf{2}}$ & 13.4 & 15.0 \\
\hline $\mathbf{3}$ & $\mathbf{\mathbf { N } _ { 3 }}$ & 12.8 & 16.1 \\
\hline \multicolumn{2}{|c|}{ Mean AUP (g/g) } & $\mathbf{1 2 . 5} \pm \mathbf{0 . 9}$ & $\mathbf{1 5 . 9} \pm \mathbf{0 . 8}$ \\
\hline
\end{tabular}

Fig 2: Fluid retention capacity after centrifugation

\begin{tabular}{|c|c|c|c|}
\hline \multirow{2}{*}{ S. No. } & \multirow{2}{*}{$\begin{array}{c}\text { Diaper } \\
\text { test } \\
\text { swatch }\end{array}$} & $\begin{array}{c}|c| \\
\text { Plain } \\
\text { Cotton } \\
\mathbf{( g / g )}\end{array}$ & $\begin{array}{c}\text { Swelling capacity (Se) } \\
\text { Carboxymethylated } \\
\text { cotton (g/g) }\end{array}$ \\
\hline $\mathbf{l}$ & $\mathbf{N}_{\mathbf{1}}$ & 4 & 13.5 \\
\hline $\mathbf{2}$ & $\mathbf{N}_{\mathbf{2}}$ & 4 & 13.5 \\
\hline $\mathbf{3}$ & $\mathbf{\mathbf { N } _ { 3 }}$ & 4 & 14.5 \\
\hline \multicolumn{2}{|c|}{ Mean Se (g/g) } & $\mathbf{4}$ & $\mathbf{1 3 . 8} \pm \mathbf{0 . 5}$ \\
\hline
\end{tabular}

Fig 3: Liquid strike through time

\begin{tabular}{|c|c|c|c|}
\hline \multirow{2}{*}{ S. No. } & \multirow{2}{*}{$\begin{array}{c}\text { Diaper } \\
\text { test } \\
\text { swatch }\end{array}$} & $\begin{array}{c}|c| \\
\text { Plain } \\
\text { cotton }\end{array}$ & $\begin{array}{c}\text { Time (s) } \\
\text { Carboxymethylated } \\
\text { Cotton }\end{array}$ \\
\cline { 3 - 4 } $\mathbf{1}$ & $\mathrm{N}_{\mathbf{1}}$ & 1.9 & 1.1 \\
\hline $\mathbf{2}$ & $\mathrm{N}_{\mathbf{2}}$ & 2.1 & 1.3 \\
\hline $\mathbf{3}$ & $\mathbf{N}_{\mathbf{3}}$ & 1.9 & 0.9 \\
\hline \multicolumn{2}{|l}{ Mean Time (S) } & $\mathbf{1 . 9} \pm \mathbf{0 . 1}$ & $\mathbf{1 . 1} \pm \mathbf{0 . 3}$ \\
\hline
\end{tabular}

Fig 4: Repeated Liquid strike through time

\begin{tabular}{|c|c|c|c|}
\hline \multirow{2}{*}{ S. No. } & \multirow{2}{*}{$\begin{array}{c}\text { Diaper } \\
\text { test } \\
\text { swatch }\end{array}$} & $\begin{array}{c}|c| \\
\text { Plain } \\
\text { cotton }\end{array}$ & $\begin{array}{c}\text { Time (s) } \\
\text { Carboxymethylated } \\
\text { Cotton }\end{array}$ \\
\cline { 3 - 4 } $\mathbf{1}$ & $\mathbf{N}_{\mathbf{1}}$ & 2.3 & 1.8 \\
\hline $\mathbf{2}$ & $\mathbf{N}_{2}$ & 2.6 & 1.9 \\
\hline $\mathbf{3}$ & $\mathbf{N}_{\mathbf{3}}$ & 2.5 & 1.7 \\
\hline \multicolumn{2}{|l}{ Mean Time (S) } & $\mathbf{2 . 4} \pm \mathbf{0 . 1}$ & $\mathbf{1 . 8} \pm \mathbf{0 . 1}$ \\
\hline
\end{tabular}

Fig 5: Wetback after Liquid strike through time

\begin{tabular}{|c|c|c|c|}
\hline \multirow{2}{*}{ S. No. } & \multirow{2}{*}{$\begin{array}{c}\text { Diaper } \\
\text { test } \\
\text { swatch }\end{array}$} & $\begin{array}{c}|c| \\
\text { Plain } \\
\text { cotton }\end{array}$ & $\begin{array}{c}\text { Weight (g/g) } \\
\text { Carboxymethylated } \\
\text { Cotton }\end{array}$ \\
\hline $\mathbf{1}$ & $\mathrm{N}_{\mathbf{1}}$ & 1.3 & 0.7 \\
\hline $\mathbf{2}$ & $\mathbf{N}_{2}$ & 1.1 & 0.7 \\
\hline $\mathbf{3}$ & $\mathbf{N}_{\mathbf{3}}$ & 1.4 & 0.8 \\
\hline \multicolumn{2}{|c}{ Mean Weight (g/g) } & $\mathbf{1 . 2} \pm \mathbf{0 . 1}$ & $\mathbf{0 . 7} \pm \mathbf{0 . 0 5}$ \\
\hline
\end{tabular}

Published By:

Blue Eyes Intelligence Engineering

\& Sciences Publication 
Table 6: Wetback after Repeated Liquid strike through time

\begin{tabular}{|c|c|c|c|}
\hline \multirow{2}{*}{ S. No. } & \multirow{2}{*}{$\begin{array}{c}\text { Diaper } \\
\text { test } \\
\text { swatch }\end{array}$} & $\begin{array}{c}|c| \\
\text { Plain } \\
\text { cotton }\end{array}$ & $\begin{array}{c}\text { Weight (g/g) } \\
\text { Carboxymethylated } \\
\text { Cotton }\end{array}$ \\
\hline $\mathbf{l}$ & $\mathbf{N}_{\mathbf{1}}$ & 1.9 & 1.6 \\
\hline $\mathbf{2}$ & $\mathbf{N}_{2}$ & 2.0 & 1.3 \\
\hline $\mathbf{3}$ & $\mathbf{N}_{\mathbf{3}}$ & 1.7 & 1.5 \\
\hline \multicolumn{2}{|l}{ Mean Weight (g/g) } & $\mathbf{1 . 8} \pm \mathbf{0 . 1}$ & $\mathbf{1 . 4} \pm \mathbf{0 . 1}$ \\
\hline
\end{tabular}

Fig 7: pH of the diaper test swatch

\begin{tabular}{|c|c|c|}
\hline S. No. & Diaper test swatch & $\mathrm{pH}$ \\
\hline 1 & $\mathrm{~N}_{1}$ & 6 \\
\hline 2 & $\mathrm{~N}_{2}$ & 7 \\
\hline 3 & $\mathrm{~N}_{3}$ & 6 \\
\hline \multicolumn{2}{|c|}{ Mean (pH) } & $\mathbf{6 . 3} \pm \mathbf{0 . 5}$ \\
\hline
\end{tabular}

Fig 8: Overall liquid transport characteristics

\begin{tabular}{|c|c|c|c|c|c|}
\hline \multirow{2}{*}{$\begin{array}{c}\text { S. } \\
\text { No }\end{array}$} & \multirow{2}{*}{$\begin{array}{c}\text { Diaper test } \\
\text { swatch }\end{array}$} & \multicolumn{2}{|c|}{ Plain cotton } & \multicolumn{2}{|c|}{$\begin{array}{c}\text { Carboxymethylated } \\
\text { Cotton }\end{array}$} \\
\cline { 3 - 6 } & & Top & Bottom & Top & Bottom \\
\hline $\mathbf{l}$ & $\mathbf{N}_{\mathbf{1}}$ & 4.2 & 46.7 & 6.3 & 39.5 \\
\hline $\mathbf{2}$ & $\mathbf{N}_{\mathbf{2}}$ & 4.5 & 44.2 & 5.7 & 40.3 \\
\hline $\mathbf{3}$ & $\mathbf{N}_{\mathbf{3}}$ & 4.3 & 45.5 & 6.0 & 37.6 \\
\hline & & $\mathbf{4 . 3} \pm$ & $\mathbf{4 5 . 4} \pm$ & $\mathbf{6 . 0 \pm}$ & $\mathbf{3 9 . 1} \pm \mathbf{0 . 3}$ \\
\hline
\end{tabular}

\section{SUMMARY AND CONCLUSION}

Cellulose is viewed as the significant casing work part of the fiber structure. It gives quality, firmness and basic dependability of the fiber. By and large strands with a higher cellulose substance builds the successful surface region of the fiber because of the evacuation of lignin, hemicelluloses and different substances have brought about bigger territory accessible for contact with the lattice offering ascend to better mechanical interlocking by giving better interfacial bond among fiber and matrix(enhanced mechanical interlocking). This prompts the improvement in the quality properties. Henceforth these filaments could be utilized as fortification for production composites with an additional favorable position of being light weight, sustainable and biodegradable.

After the alteration of the cellulose strands they will demonstrate a similar conduct as too spongy polymers (SAP) and the ingestion instrument of liquids are the equivalent. Ionic polymers, for example, those made by the alteration of the cellulose are electrically nonpartisan because of that the negative carboxylate gatherings are killed by the positive sodium particles. At the point when the polymer interact with water the sodium particles winds up hydrated and lose their appreciation for the carboxylate gatherings, this make it workable for the sodium particles to move around in the polymer organize. This development offers ascend to an osmotic weight inside the gel. The most extreme swelling will happen for deionizer water, if the liquid contains high convergence of salt there will be no or small swelling since the osmotic impact will be little.

\section{REFERENCES}

1. Cellulose : molecular and structural biology : selected articles on the synthesis, structure, and applications of cellulose. Brown, R. Malcolm (Richard Malcolm), 1939-, Saxena, I. M. (Inder M.). Dordrecht: Springer. 2007. ISBN 9781402053801. OCLC 187314758.

2. Bureau of Indian Standards IS: 5405 (1980) - Diapers [MHD 14: Hospital Planning].

3. Diapering Your Baby. Kidshealth.org. Retrieved on April 9, 2013

4. Kabiri, K. (2003). "Synthesis of fast-swelling superabsorbent hydrogels: effect of crosslinker type and concentration on porosity and absorption rate". European $\begin{array}{llll}\text { Polymer Journal. } 39 & \text { (7): } & \text { 1341-1348. }\end{array}$ doi:10.1016/S0014-3057(02)00391-9

5. Technical Brochure of Superabsorbent Polymer Research Lab., Nippon Shokubai Co., www.shokubai.co.jp, available in 15 August. 2005.

6. Mohammad J. Zohuriaan-Mehr and KouroshKabiri Superabsorbent Polymer Materials: A Review Iranian Polymer Journal. 17 (6), 2008, 451-477.

7. Shanmugasundaram OL. 2010. Development and characterization of bamboo and organic cotton fibre blended baby diapers. Indian Journal of Fibre and Textile Research. 35: 201-205.

8. G.Sasikumar, M.Senthil, K.Visagavel, H. Abdul Zubar, T.Dheenathayalan. DEVELOPMENT OF BIO-DEGRADABLE BABY DIAPERS. International Journal of Research in Engineering and Technology. Volume: 03 Special Issue: 11 Pg 186 - 191.

9. Reza Masoodi, Krishna M. Pillai and Padma P. Varanasi. Effect of Externally Applied Liquid Pressure on Wicking in Paper Wipes. Journal of Engineered Fibers and Fabrics.Volume 5, Issue 3 - 2010. 